\title{
Comparação microscópica e proliferativa de fibroblastos gengivais de pacientes com gengiva normal e com fibromatose gengival hereditária
}

\section{Microscopic and proliferative comparison of gingival fibroblasts from patients with normal gingiva and with hereditary gingival fibromatosis}

\author{
Hercilio MARTELLI-JUNIOR* \\ Glaucia BOLZANI* \\ Edgard GRANER** \\ Lourenço BOZZO** \\ Ricardo Della COLETTA**
}

\begin{abstract}
MARTELLI-JUNIOR, H.; BOLZANI, G.; GRANER, E.; BOZZO, L.; COLETTA, R. D. Comparação microscópica e proliferativa de fibroblastos gengivais de pacientes com gengiva normal e com fibromatose gengival hereditária. Pesq Odont Bras, v. 14, n. 2, p. 123-129, abr./jun. 2000.
\end{abstract}

\begin{abstract}
Fibromatose gengival hereditária (FGH) é uma condição bucal rara clinicamente manifestada por um aumento gengival generalizado e fibrótico, podendo apresentar-se de forma isolada ou associada a outras alterações, como parte de síndromes. Os mecanismos biológicos envolvidos na FGH são desconhecidos, e os resultados de estudos de cultura celulares são controversos. Para elucidar as características fenotípicas dos fibroblastos de FGH, nós isolamos quatro linhagens celulares de fibroblastos de FGH de indivíduos de uma mesma família e comparamos as características morfológicas e proliferativas com fibroblastos provenientes de pacientes com gengiva clinicamente normal (GN). Fibroblastos de GN e FGH em condições de subconfluência celular apresentaram típicas características morfológicas, como formato fusiforme, núcleo central e longos prolongamentos citoplasmáticos, mas em condições de saturação da densidade celular, os fibroblastos de FGH apresentaram dimensões menores que as células controle. A relação núcleo/citoplasma foi sempre menor para todas as linhagens celulares de fibroblastos de FGH, sugerindo que a redução celular, é proveniente de uma redução ou compactação citoplasmática e não nuclear. A capacidade proliferativa de fibroblastos de FGH foi maior que a de fibroblastos de GN. Estes resultados sugerem que diferenças morfológicas e proliferativas dos fibroblastos de FGH podem estar associadas aos eventos biológicos envolvidos na etiopatogenia do aumento gengival observado em pacientes com FGH.
\end{abstract}

UNITERMOS: Fibromatose gengival; Fibroblastos; Cultura de células.

\section{INTRODUÇÃO}

Fibromatose gengival é um termo genérico usado clinicamente para identificar um aumento volumétrico da gengiva, freqüentemente resultado do acúmulo de grandes quantidades de colágeno ${ }^{22}$. A fibromatose gengival é classificada em iatrogênica, idiopática, inflamatória, medicamentosa e hereditária. A fibromatose gengival de caráter hereditário é denominada de fibromatose gengival hereditária (FGH).

$\mathrm{O}$ primeiro relato de $\mathrm{FGH}$ que se tem conhecimento ocorreu em 1856 com Gross. A partir deste relato, inúmeros outros trabalhos têm procurado caracterizar clínica, microscópica, bioquímica e geneticamente a FGH. Entretanto, os resultados de estudos que caracterizam a FGH são controversos. A FGH é uma condição rara $(1: 750.00)^{21}$, de crescimento lento, que se manifesta clinicamente por aumento gengival firme, indolor, não hemorrágico, de coloração rósea e pontilhado superficial característico que pode recobrir parcial ou totalmente a coroa dental e que não apresenta tendência a regressão espontânea ${ }^{2,3}$. A gravidade do aumento gengival é variável, podendo variar de leve a grave mesmo em indivíduos de uma mesma

* Pós-Graduandos; ** Professores - Departamento de Patologia Oral da Faculdade de Odontologia de Piracicaba da UNICAMP. 
MARTELLI-JUNIOR, H.; BOLZANI, G.; GRANER, E.; BOZZO, L.; COLETTA, R. D. Comparação microscópica e proliferativa de fibroblastos gengivais de pacientes com gengiva normal e com fibromatose gengival hereditária. Pesq Odont Bras, v. 14, n. 2, p. $123-129$, abr./jun. 2000 .

família ${ }^{21}$. Este aumento pode ser generalizado, isto é, envolver todos os dentes de ambos os arcos, ou parcial, envolver somente um arco ou porções de um arco. O envolvimento localizado é mais freqüente na superficie palatina da tuberosidade maxilar e na superficie lingual da mandíbula.

A FGH é transmitida de forma heterogênea, podendo manifestar de forma isolada ou mais raramente, como componente de sindromes. A alteração mais comumente observada em associação a FGH é a hipertricose, a qual está ocasionalmente associada a retardo mental e epilepsia. A FGH geralmente apresenta um modo de herança autossômico dominante, contudo, o gene demonstra variáveis graus de penetrância e expressividade. Formas autossômicas recessivas são ocasionalmente relatadas ${ }^{6,7}$.

Há consenso geral que o aumento gengival é proveniente de uma hiperplasia não inflamatória dos elementos do tecido conjuntivo. Densos e numerosos feixes de fibras colágenas mostram-se entrelaçados e permeados por fibroblastos, vasos sangüíneos e ocasionalmente, discreto infiltrado inflamatório. O epitélio pavimentoso estratificado paraqueratinizado encontra-se hiperplásico e, profundas e delgadas criptas epiteliais projetam-se em direção ao conjuntivo subjacente ${ }^{5,18}$.

O objetivo deste estudo foi isolar e comparar as características morfológicas e proliferativas de culturas primárias de fibroblastos gengivais de quatro pacientes de uma mesma família com FGH com fibroblastos gengivais de pacientes com gengiva clinicamente normal (GN).

\section{MATERIAL E MÉTODO Pacientes}

Foram analisados fibroblastos gengivais de pacientes com GN e com FGH. Tecido gengival normal foi obtido através de biópsias por "punch", entre os dentes 13 e 14, dois a três milímetros acima da margem gengival livre. Foram selecionados apenas os individuos que apresentaram gengiva clinicamente normal sem evidências de inflamação ou hiperplasia, e ausência de história de uso de medicamentos relacionados a aumento gengival. A gengiva dos pacientes portadores de FGH foi coletada durante tratamento cirúrgico de rotina (gengivectomias e gengivoplastias) no serviço de atendimento de pacientes especiais Orocentro/FOP - UNICAMP. Todos os pacientes com FGH foram de uma mesma família, e apenas foram selecionados os in- divíduos com aumento gengival generalizado de aspecto fibroso e sem sinais de inflamação. A Tabela 1 mostra as informações clínicas das linhagens celulares de fibroblastos gengivais. Todos os procedimentos foram realizados de acordo com as normas relativas à ética em pesquisa envolvendo seres humanos - deliberação do Comitê de Ética em Pesquisa da Faculdade de Odontologia de Piracicaba - UNICAMP.

Os tecidos gengivais foram seccionados em 2 fragmentos, sendo um utilizado para estabelecimento das culturas primárias de fibroblastos e o outro para análise histopatológica. O material enviado para processamento histopatológico foi fixado em formalina à $10 \%$, embebido em parafina, seccionado em cortes de $5 \mu \mathrm{m}$ de espessura e corados com a técnica de hematoxilina e eosina (H. E.).

\section{Cultura primária}

Fragmentos gengivais de pacientes normais e com FGH foram removidos e imersos em meio de cultura de Eagle modificado por Dulbecco's (DMEM, Sigma Chemical Co., St. Louis, MO, USA) acrescido de $10 \%$ soro fetal bovino (Cultilab Ltda., Campinas - SP), $125 \mathrm{mg} / \mathrm{ml}$ ampicilina G e $50 \mathrm{ng} / \mathrm{ml}$ anfotericina $\mathrm{B}$ à $4^{\circ} \mathrm{C}$ e levados imediatamente a geladeira, onde foram mantidos por $16 \mathrm{~h}$. Os fragmentos foram lavados três vezes na mesma solução, cortados em fragmentos de aproximadamente $1 \mathrm{~mm}^{3}$ e transferidos para frascos de cultura de $25 \mathrm{~cm}^{2}$, que foram mantidos à temperatura

TABELA 1 - Características clínicas dos pacientes.

\begin{tabular}{|c|c|c|c|c|c|}
\hline \multicolumn{2}{|c|}{$\begin{array}{l}\text { Linhagem } \\
\text { celular }\end{array}$} & \multirow{2}{*}{$\frac{\text { Sexo }}{\text { F }}$} & \multirow{2}{*}{$\begin{array}{c}\text { Idade } \\
29\end{array}$} & \multirow{2}{*}{$\begin{array}{c}\text { Localização } \\
13-14\end{array}$} & \multirow{2}{*}{$\begin{array}{c}\begin{array}{c}\text { Graduação } \\
\text { clínica* }\end{array} \\
0\end{array}$} \\
\hline \multirow{4}{*}{ 递 } & GN1 & & & & \\
\hline & GN3 & $\mathrm{M}$ & 26 & $13-14$ & 0 \\
\hline & GN4 & $\mathrm{M}$ & 26 & $13-14$ & 0 \\
\hline & GN5 & M & 23 & $13-14$ & 0 \\
\hline \multirow{4}{*}{$\underset{T}{\mathbb{T}}$} & FGH2 & $\mathrm{F}$ & 28 & $34-36$ & 1 \\
\hline & FGH3 & M & 22 & $13-23$ & 2 \\
\hline & FGH5 & M & 20 & $13-23$ & 2 \\
\hline & FGH7 & $\mathrm{M}$ & 18 & $33-34$ & 2 \\
\hline
\end{tabular}

*Graduação clínica: (0) excelente condição gengival, sem sinais de inflamação ou hiperplasia gengival; (1) aumento gengival leve; (2) aumento gengival moderado; e (3) aumento gengival agressivo. Classificação segundo MACHADO ${ }^{14}, 1996$. 
MARTELLI-JUNIOR, H.; BOLZANI, G.; GRANER, E.; BOZZO, L.; COLETTA, R. D. Comparação microscópica e proliferativa de fibroblastos gengivais de pacientes com gengiva normal e com fibromatose gengival hereditária. Pesq Odont Bras, v. 14, n. 2, p. 123-129, abr./jun. 2000.

de $37^{\circ} \mathrm{C}$, atmosfera úmida contendo $5 \% \mathrm{CO}_{2}$. O crescimento celular foi monitorado diariamente e o meio de cultura trocado a cada 2 ou 3 dias, de acordo com o metabolismo celular. A concentração de ampicilina $\mathrm{G}$ foi reduzida para $50 \mathrm{mg} / \mathrm{ml}$ após 15 dias de cultivo. Após atingirem a subconfluência, as células foram subcultivadas. No subcultivo, o meio de cultura foi removido e as células lavadas em solução de tampão fosfato salino $\mathrm{pH}$ 7,4 (PBS) acrescido de 0,5 mM ácido etilenodiamino tetracético (Sigma). Em seguida, as células foram separadas do assoalho da garrafa de cultura pela adição de $1 \mathrm{ml}$ de tripsina (Sigma) à $0,2 \%$. A tripsina foi inativada com $10 \mathrm{ml}$ de meio de cultura acrescido de $10 \%$ soro fetal bovino. A suspensão de células foi então centrifugada a $400 \mathrm{~g}$ por $2 \mathrm{~min}$, o sobrenadante descartado e as células ressuspensas e plaqueadas em lâminas de vidro preparadas para cultura (LabTek - Nunc. Int., Naperville IL, USA). Transcorrido 24 h, as células de GN e FGH aderidas as lâminas foram fixadas em $70 \%$ etanol, coradas pela técnica convencional de H. E. e examinadas à microscopia de luz. Em todos os procedimentos de cultivo foram observados cuidados para a manutenção da esterilidade.

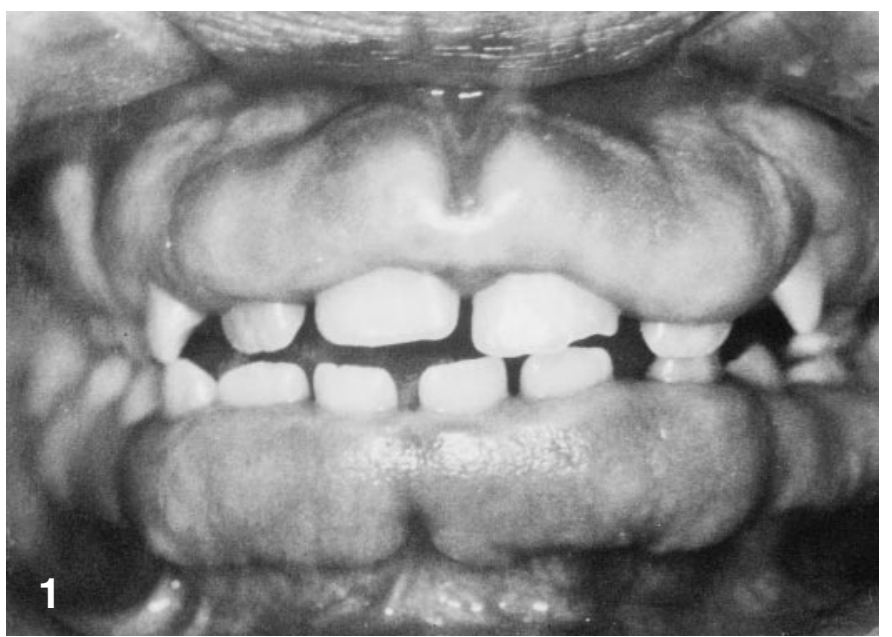

FIGURA 1 - Foto clínica de um dos pacientes com FGH deste estudo. Note a severa e generalizada hiperplasia gengival envolvendo todos os dentes de ambos os maxilares. Os dentes são morfologicamente normais e não são observadas quaisquer alterações radiográficas.

FIGURA 2 - Fotomicrografia da gengiva obtida após gengivectomia/gengivoplastia do paciente da Figura 1. A hiperplasia gengival é proveniente de um acentuado aumento no número de feixes de fibras colágenas do tecido conjuntivo. O epitélio apresentou hiperplasia e profundas e delgadas criptas epiteliais projetam em direção ao conjuntivo (H. E., $250 \mathrm{X}$ ).

\section{Análise de crescimento celular}

Fibroblastos de GN e FGH (1.000; 2.000; 4.000; $6.000 ; 8.000 ; 10.000$ células) em meio de cultura foram plaqueados em triplicata em "wells" de uma placa de cultura de 24 - "wells" (Corning Sci. Prod. Inc., Acton MA, USA) e incubados à $37^{\circ} \mathrm{C}$, atmosfera úmida contendo $5 \% \mathrm{CO}_{2}$. Transcorrido $16 \mathrm{~h}$ de incubação, os "wells" foram gentilmente lavados com PBS e o meio de cultura substituído por DMEM contendo $1 \%$ soro fetal bovino. Após $16 \mathrm{~h}$, as células foram novamente incubadas com DMEM acrescido de 10\% soro fetal bovino. Após 4 dias de proliferação, as células foram separadas do assoalho da placa de cultura pela adição de $1 \mathrm{ml}$ de uma solução de tripsina à $0,2 \%$ em PBS. O índice de crescimento celular foi determinado por contagem da população celular em câmara de Neubauer. Este ensaio foi realizado em triplicata.

\section{RESULTADOS}

Clinicamente os indivíduos afetados por FGH apresentaram aumento gengival de aspecto fibroso com crescimento lento e progressivo. Em todos os casos, o aumento gengival foi generalizado sendo a

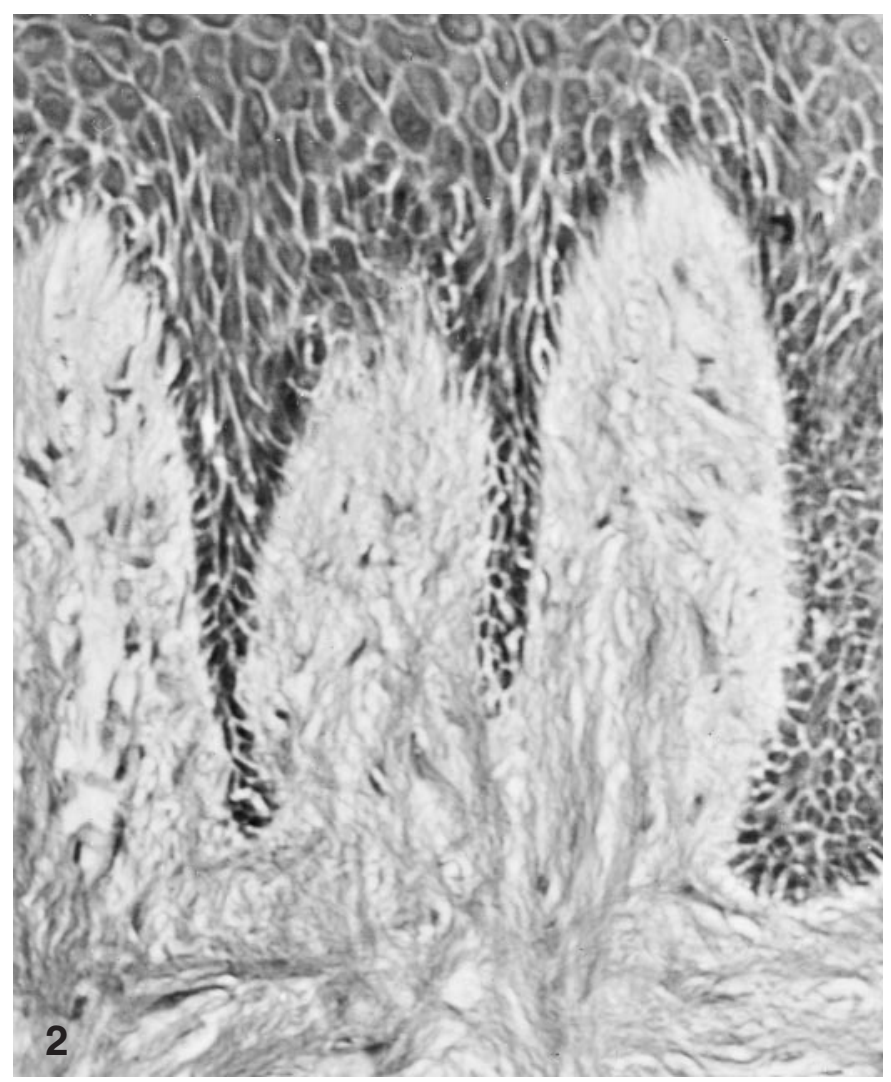


MARTELLI-JUNIOR, H.; BOLZANI, G.; GRANER, E.; BOZZO, L.; COLETTA, R. D. Comparação microscópica e proliferativa de fibroblastos gengivais de pacientes com gengiva normal e com fibromatose gengival hereditária. Pesq Odont Bras, v. 14, n. 2, p. $123-129$, abr./jun. 2000 .

região anterior o sítio de maior agressividade (Figura 1). O tecido gengival removido cirurgicamente mostrou típicas características microscópicas. Comparando com a gengiva de pacientes do grupo controle, a gengiva de indivíduos com FGH mostrou um tecido conjuntivo fibroso com densos e numerosos feixes de fibras colágenas. O epitélio acantótico e hiperplásico projeta em direção ao tecido conjuntivo formando longas e delgadas e, muitas vezes, irregulares criptas epiteliais (Figura 2). As características microscópicas foram similares para todos os pacientes.

Os fibroblastos de FGH apresentaram velocidade de crescimento maior que fibroblastos de GN. Fibroblastos gengivais foram observados emergindo de todos os fragmentos de FGH em média após 18 dias, e dos fragmentos de GN após 25 dias. Após 30 a 35 dias de cultura primária, mais que 90\% do frasco estava preenchido com fibroblastos de FGH, sendo então realizado a primeira subcultura. Por outro lado, a cultura de GN cresceu mais lentamente e a primeira subcultura só foi possivel após 42 dias do início do cultivo. Tanto na cultura primária quanto nas subculturas, foi evidente que fibroblastos de FGH proliferaram mais rapidamente que fibroblastos de GN. Após a décima subcultura foi observado uma redução na velocidade de crescimento, e próximo a décima quinta, tanto as células de FGH quanto as de GN, não mais progrediram como inicialmente, sendo então descartadas.

As células de FGH e GN, apesar da diferença de velocidade de crescimento, proliferaram em orientação paralela respeitando o espaço que deve normalmente existir entre as membranas celulares e, em condições de confluência celular não foi observado empilhamento, desorganização na distribuição ou morte celular. Morfologicamente em condições de subconfluência celular, os fibroblastos de FGH e GN foram similares. Exibiram formato fusiforme com núcleo central e típicos prolongamentos citoplasmáticos. Porém, em condições de confluência celular, os fibroblastos de FGH demonstraram tamanho e largura menores que fibroblastos de GN. A coloração das células pela técnica convencional de $\mathrm{H}$. E. e análise em microscopia de luz demonstrou que, a redução no volume celular dos fibroblastos de FGH em condições de confluência celular é resultado da redução no volume citoplasmático, e não no volume nuclear (Figura 3). A relação núcleo/citoplasma sempre foi maior para as linhagens de fibroblastos de GN quando comparado com as linhagens de fibroblastos de FGH.

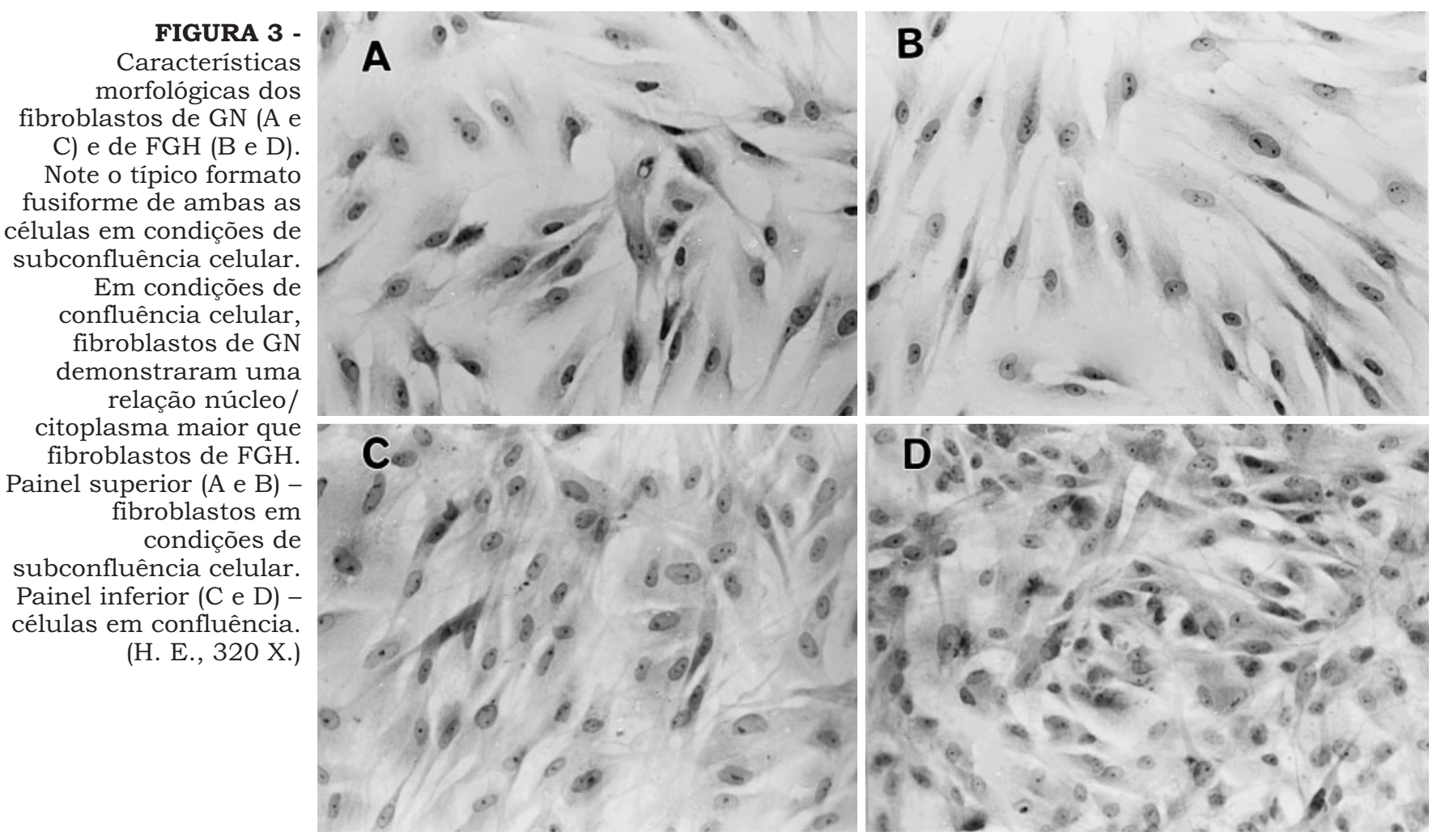


MARTELLI-JUNIOR, H.; BOLZANI, G.; GRANER, E.; BOZZO, L.; COLETTA, R. D. Comparação microscópica e proliferativa de fibroblastos gengivais de pacientes com gengiva normal e com fibromatose gengival hereditária. Pesq Odont Bras, v. 14, n. 2, p. $123-129$, abr./jun. 2000 .

Fibroblastos de GN e FGH foram plaqueados em concentração variando de $1 \times 10^{3}$ a $10^{4}$ células/"well" em placas de cultura de 24-"wells" e incubados por $16 \mathrm{~h}$ em DMEM/10\% soro fetal bovino, seguido por incubação adicional de $16 \mathrm{~h} \mathrm{em}$ soro fetal bovino à $1 \%$. Um período de incubação em meio de cultura na ausência soro fetal bovino ou a niveis reduzidos é requerido previamente a estimulação celular no objetivo de cessar as vias de ativação da proliferação celular por fatores de crescimento presentes no soro. É demonstrado que periodos superiores a $4 \mathrm{~h}$ de ausência da influência de soro fetal bovino são suficientes para reduzir o metabolismo celular a niveis basais com conseqüente inibição da proliferação, sem aparente prejuízo na viabilidade celular ${ }^{13}$. A análise proliferativa de fibroblastos provenientes de GN e FGH é mostrada na Figura 4. Diferenças na relação de proliferação foi observada para todas as concentrações celulares analisadas.

\section{DISCUSSÃO}

Hiperplasia gengival generalizada pode estar associada com o uso de drogas como fenitoína, ciclosporina e nifedipina ${ }^{15}$, ou associada a condições inflamatórias e tumorais ${ }^{19}$ ou pode ainda ser transmitida de forma hereditária, como componente ou não de uma sindrome ${ }^{7}$. No grupo estudado, a hiperplasia gengival generalizada foi transmitida de forma autossômica dominante e nenhum dos indivíduos apresentou qualquer outra alteração comumente relatada em associação a fibromatose gengi$\mathrm{val}^{3}$. As características clínicas e microscópicas dos pacientes com FGH foram similares as descritas previamente na literatura.

FGH é caracterizada por um aumento gengival generalizado com deposição e acúmulo excessivos de colágeno. Os mecanismos celulares envolvidos nesta alteração não são ainda conhecidos. No presente estudo, fibroblastos gengivais de 4 membros de uma mesma família afetada com FGH foram isolados e cultivados e alguns pontos foram de interesse. Primeiro, o tempo inicial necessário para que os fragmentos gengivais aderissem aos frascos de cultura de plástico e para que as células começassem a emergir dos fragmentos foram diferentes entre fibroblastos de GN e FGH (aproximadamente 10 dias). Segundo, os fibroblastos de FGH apresentaram nas etapas de cultura primária e subcultivo velocidade de crescimento maior que fibroblastos de GN. Apesar desta diferença, os fibroblastos de GN apresentaram comportamento

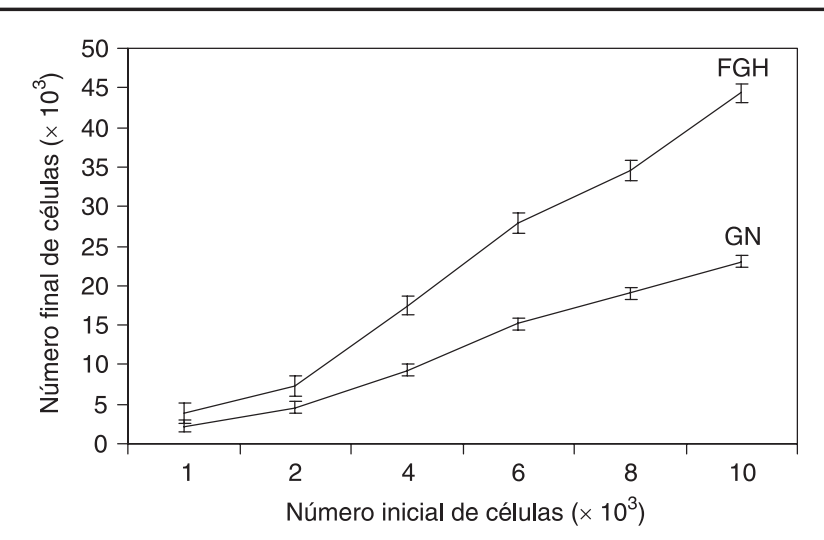

FIGURA 4 - Relação de crescimento celular para fibroblastos de GN e FGH. Fibroblastos de GN e FGH foram plaqueados em diferentes concentrações celulares, como mencionado em Material e Métodos, e cultivados por 4 dias. Em seguida, a população celular foi determinada por contagem utilizando-se câmara de Neubauer. Para todas as concentrações celulares analisadas, diferenças no número de células em culturas de fibroblastos de FGH foi sempre maior que culturas de células normais.

característico de célula normal, inclusive com inibição por contato da proliferação celular. Terceiro, fibroblastos de GN e FGH apresentaram similares características morfológicas em condições de subconfluência celular, enquanto que em condições de confluência, fibroblastos de FGH apresentam uma relação núcleo/citoplasma menor que fibroblastos controle.

Existem poucos estudos na literatura avaliando os fibroblastos gengivais isolados de pacientes com FGH. JOHNSON et al. ${ }^{11}$ (1986) foram os primeiros a isolar e caracterizar os fibroblastos de uma menina com hiperplasia gengival generalizada associada a hipertricose, macroglossia e alterações faciais. Os fibroblastos isolados por JOHNSON et al. ${ }^{11}$ (1986) demonstraram alterações nucleares de tamanho e vida celular em cultura curta, além de proliferarem mais lentamente quando comparados com células de GN. A quantidade de proteína total sintetizada por estas células foi a mesma que nas células normais, mas a quantidade de colágeno foi apenas a metade da produzida por células controle. SHIRASUNA et al. ${ }^{20}$ (1989) também isolaram e caracterizaram fibroblastos de dois irmãos afetados com FGH generalizada. Em análise por microscopia de contraste de fase, estes autores não observaram diferenças entre fibroblastos de GN e FGH. Entretanto, a microscopia eletrônica demonstrou que fibroblastos de FGH 
MARTELLI-JUNIOR, H.; BOLZANI, G.; GRANER, E.; BOZZO, L.; COLETTA, R. D. Comparação microscópica e proliferativa de fibroblastos gengivais de pacientes com gengiva normal e com fibromatose gengival hereditária. Pesq Odont Bras, v. 14, n. 2, p. $123-129$, abr./jun. 2000 .

apresentam os retículos endoplasmáticos, mitocôndrias e aparelhos de Golgi mais desenvolvidos que fibroblastos de GN. COLLAN et al. ${ }^{4}$ (1982) descreveram através de microscopia eletrônica, subpopulações de fibroblastos gengivais em FGH. Estes autores identificaram dois tipos distintos de fibroblastos: fino, associado às áreas ricas em matriz extracelular, mas pobre em fibras colágenas; e o grosso, aparentemente inativo, mas rico em fibras colágenas. Os fibroblastos nas áreas com grande quantidade de colágeno continham retículo endoplasmático rugoso e aparelho de Golgi dilatados e proeminentes, numerosas mitocôndrias e microfilamentos citoplasmáticos.

HASSELL; COOPER ${ }^{8}$ (1980) e posteriormente PHIPPS et al. ${ }^{17}$ (1997) propuseram a teoria das subpopulações celulares para explicar a patogênese dos vários tipos de aumentos gengivais. Estes autores demonstraram que existem subpopulações de fibroblastos gengivais com diferenças genotípicas e funcionais, mas com muitas similaridades morfológicas, em tecidos normais e alterados. Esta hipótese de diferentes subpopulações celulares é suportada por diferenças significantes nos níveis de produção de várias moléculas da matriz extracelular como colágeno, fibronectina, proteoglicanos e glicosaminoglicanos ${ }^{1,9,10,12,16}$. Estes estudos sugerem que alterações no tecido conjuntivo gengival podem ser resultado da estimulação e da instabilidade das subpopulações de fibroblastos residentes, e não, da presença de um novo tipo alterado, sendo que as proporções dos vários subtipos celulares e as atividades podem ser reguladas por mediadores químicos tal como citocinas.
A identificação de linhagens de fibroblastos com heterogeneidade genotípica e fenotípica, diferindo em características morfológicas e proliferativas, é essencial para o melhor entendimento dos eventos biológicos que resultam no aumento gengival de pacientes com FGH. Dentro desta observação, estudos de culturas celulares são fundamentais para este entendimento.

\section{CONCLUSÕES}

1. Fibroblastos de GN e FGH apresentam em condições de subconfluência celular características morfológicas semelhantes, porém, em condições de saturação da densidade celular, fibroblastos de FGH apresentam uma relação núcleo/citoplasma menor que células isoladas de pacientes com GN.

2. Linhagens celulares de fibroblastos de FGH apresentaram uma velocidade proliferativa maior que linhagens de fibroblastos de GN.

3. Apesar das diferenças morfológicas e da velocidade de crescimento, fibroblastos de FGH apresentam inibição da proliferação por contato.

4. Estudos de cultura de células representam importantes ferramentas laboratoriais para o melhor entendimento dos eventos biológicos relacionados com doenças específicas, como por exemplo a FGH.

\section{AGRADECIMENTOS}

Os alunos Hercílio Martelli Junior e Glaucia Bolzani são bolsistas da Fundação de Amparo à Pesquisa do Estado de São Paulo - FAPESP, processo número 98/02234 e 97/06364, respectivamente.

\footnotetext{
MARTELLI-JUNIOR, H.; BOLZANI, G.; GRANER, E.; BOZZO, L.; COLETTA, R. D. Microscopic and proliferative comparison of gingival fibroblasts from patients with normal gingiva and with hereditary gingival fibromatosis. Pesq Odont Bras, v. 14, n. 2, p. 123-129, abr./jun. 2000.
}

Hereditary gingival fibromatosis (HGF) is a rare oral condition, clinically manifested through a generalized and fibrotic enlargement of the gingiva, which may present as an isolated clinical finding or in association with other features, as part of a syndrome. The biological mechanisms involved in HGF are unknown, and the results of cell-culture studies are controversial. To elucidate the phenotypic and proliferative characteristics of HGF fibroblasts, we isolated 4 cell lines of gingival fibroblasts from members of the same family with HGF, and compared with gingival fibroblasts from 4 healthy patients (NG). HGF and NG fibroblasts, in subconfluent culture densities, showed typical morphological characteristics, such as spindle form with a central spherical nucleus and long cytoplasmatic prolongations, but in saturation density, HGF cells were shorter than control cells. The nucleus/cytoplasm relation was always smaller in all HGF cell lines, suggesting that the cellular reduction is derived from reduction or compaction of the cytoplasm and not of the nucleus. The proliferation rate was higher in fibroblasts from HGF than in the ones from NG. These results suggest that differences in the morphology and proliferation of HGF fibroblasts may be associated with the biological events involved in the pathogenesis of gingival overgrowth in HGF patients.

UNITERMS: Fibromatosis, gingival; Fibroblasts; Cell culture. 
MARTELLI-JUNIOR, H.; BOLZANI, G.; GRANER, E.; BOZZO, L.; COLETTA, R. D. Comparação microscópica e proliferativa de fibroblastos gengivais de pacientes com gengiva normal e com fibromatose gengival hereditária. Pesq Odont Bras, v. 14, n. 2, p. $123-129$, abr./jun. 2000 .

\section{REFERÊNCIAS BIBLIOGRÁFICAS}

1. BORDIN, J. S.; PAGE, R. C.; NARAYANAN, A. S. Heterogeneity of human diploid fibroblasts: isolation and characterization of one phenotype. Science, v. 223, n. 5, p. 171-173, May 1984.

2. BOZZO, L.; ALMEIDA, O. P.; SCULLY, C. Familial gingival hyperplasia: a case of pseudo-Laband syndrome. Periodontal Clin Investig, v. 14, n. 6, p. 23-24, Sept. 1992.

3. BOZZO, L.; ALMEIDA, O. P.; SCULLY, C. et al. Hereditary gingival fibromatosis: report of an extensive four-generation pedigree. Oral Surg Oral Med Oral Pathol, v. 78, n. 3, p. 452-454, Mar. 1994.

4. COLLAN, Y.; RANTA, H.; VARTIO,T. Histochemical and biochemical study of hereditary fibrous hyperplasia of the gengiva. Scan J Dent Res, v. 90, n. 8, p. 20-25, Aug. 1982.

5. DANESH-MEYER, M. J.; HOLBOROW, D. W. Familial gingival fibromatosis: a report of two patients. N Z Dent J, v. 89, n. 11, p. 119-122, Sept. 1993.

6. GOLDBLAT, J.; SINGER, S. L. Autossomal recessive gingival fibromatosis with distinctive facies. Clin Genet, v. 42, n. 7, p. 306-308, Jan. 1992

7. GORLIN, R. J.; COHEN, M. M. J.; LEVIN, L. S. Syndromes of the head and neck. 1. ed. New York : Oxford University Press, 1990. $977 \mathrm{p}$.

8. HASSEL, T. M.; COOPER, G. C. Phenytoin-induced gingival overgrowth in mongrel cat model. In: HASSELL, T. M.; JOHNSON M. C.; DUDLEY K. H., eds. Phenytoin Induced Teratology and Gingival Pathology. New York : Raven Press, 1980. p. 147-162.

9. HASSEL, T. M.; PAGE, R. C.; NARAYANAN, A. S. et al. Diphenylhydantoin (Dilantin) gingival hyperplasia: drug-induced abnormality of connective tissue. Proc Natl Acad Sci USA, v. 73, n. 4, p. 2909-2912, Aug. 1976.

10. HASSEL, T. M.; STANEK, E. J. Evidence that healthy human gingiva contains functionally heterogenous fibroblasts subpopulations. Arch Oral Biol, v. 28, n. 3, p. 617-625, Nov. 1983.

11. JOHNSON, B. D.; EI-GUINDY, M.; AMMONS, W. F. et al. A defect in fibroblasts from an unidentified syndrome with gingival hyperplasia as the predominant feature. J Periodontal Res, v. 21, n. 8, p. 403-413, July 1986.
12. KO, S. D.; PAGE, R. C.; NARAYANAN, A. S. Fibroblast heterogeneity and prostaglandin regulation of subpopulations. Proc Natl Acad Sci USA, v. 74, n. 6, p. 3429-3432, Oct. 1977.

13. McALLISTER, BS.; LEEB-LUNDBERG, F.; MELLONIG, J. $\mathrm{T}$. et al. The functional interaction of EGF and PDGF with bradykinin in the proliferation of human gingival fibroblasts. J Periodontol, v. 66, p. 429-437, Sept. 1995.

14. MACHADO, M. A. N. Análise dos heredogramas e das correlações clínicas da fibromatose gengival hereditária, numa familia de 219 pessoas. Piracicaba, 1996. 78 p. Dissertação (Mestrado) - Faculdade de Odontologia de Piracicaba, Universidade Estadual de Campinas.

15. MARSHALL, R. I.; BARTHOLD, P. M. Medication induced gingival overgrowth. Oral Disease, v. 4, n. 3, p. 130-151, Oct. 1998.

16. NARAYANAN, A. S.; PAGE, R. C. Synthesis of type V collagen by fibroblasts derived from normal, inflamed and hyperplastic human connective tissues. Collagen Rel Res, v. 5, n. 2, p. 297-304, Aug. 1985.

17. PHIPPS, R. P.; BORRELO, M. A.; BLIEDEN, T. M. Fibroblast heterogeneity in the periodontium and other tissues. J Periodontal Res, v. 32, n. 9, p. 159-165, Sept. 1997.

18. REDMAN, R. S.; WARD, C. C.; PATERSSON, R. H. Focus of epithelial dysplasia arising in hereditary gingival fibromatosis. J Periodontol, v. 56, n. 8, p. 158-162, Sept. 1985.

19. REGEZI, J. A.; SCIUBBA, J. J. Oral Pathology: clinical pathologic correlations. Philadelphia : Saunders, 1999. $554 \mathrm{p}$.

20. SHIRASUNA, K.; OKURA, M.; WATANABI, K. et al. Abnormal cellular property of fibroblasts from congenital gingival fibromatosis. J Oral Pathol, v. 7, n. 5, p. 381-385, Mar. 1989.

21. SINGER, S. L.; GOLDBLATT, J.; HALLAN, L. A. et al. Hereditary gingival fibromatosis with a recessive mode of inheritance. Case reports. Aust Dent J, v. 38, n. 7, p. 427-432, Aug. 1993.

22. TAKAGI, M.; YAMAMOTO, H.; MEGA, H. et al. Heterogeneity in gingival fibromatosis. Cancer, v. 68, n. 4, p. 2202-2212, Feb. 1991. 